\title{
Technology diffusion, abatement cost, and transboundary pollution
}

\author{
Geoffrey Heal ${ }^{\mathrm{a}}$ \\ Graduate School of Business \\ Columbia University \\ and \\ Nori Tarui ${ }^{\mathrm{b}}$ \\ Department of Economics \\ University of Hawai'i at Mānoa
}

October 2008

\begin{abstract}
This paper studies countries' incentives to develop advanced pollution abatement technology when technology may spillover across countries and pollution abatement is a global public good. We are motivated in part by the problem of global warming: a solution to this involves providing a global public good, and will surely require the development and implementation of new technologies. We show that at the Nash equilibrium of a simultaneous-move game with R\&D investment and emission abatement, whether the free rider effect prevails and under-investment and excess emissions occur depends on the degree of technology spillovers and the effect of R\&D on the marginal abatement costs. There are cases in which, contrary to conventional wisdom, Nash equilibrium investments in emissions reductions exceed the first-best case.
\end{abstract}

Keywords: International environmental agreement; pollution abatement costs; endogenous technological change.

JEL codes: Q50, H87, D70

\footnotetext{
${ }^{a}$ Graduate School of Business, Columbia University, 616 Uris Hall, New York, NY 10027, USA. Email: gmh1@columbia.edu.Graduate School of Business, Columbia University, 616 Uris Hall, New York, NY 10027, USA. Email: gmh1@columbia.edu.

${ }^{\mathrm{b}}$ Department of Economics, University of Hawai'i at Mānoa, 2424 Maile Way, Honolulu, HI 96822, USA. Email: nori@hawaii.edu.
} 


\section{Introduction}

This paper is motivated in part by the problem of global warming: a solution will involve providing a global public good, and will surely require the development of new technologies and their implementation both in the countries that develop them and in others. We examine how the effect of technological innovation on the cost structure of emission abatement influences the countries' incentives to reduce emissions, to invest in $R \& D$, and share new technologies with other countries. To analyze these issues, we use a simultaneous-move game of emissions reduction and R\&D investments where each country acts noncooperatively. We hope that the intuitions we develop here can be valuable in managing the R\&D process and structuring international agreements on this topic.

In the context of climate change, most studies on emission control and technological innovation predict that scenarios without policy intervention involve excessive emissions and insufficient $R \& D$ relative to the first best levels. It is not widely recognized that a crucial assumption behind this prediction is that the marginal abatement cost decreases as technology improves. In fact this need not be the case: we provide examples of technological changes which imply smaller total abatement costs but larger marginal abatement costs. Using a simultaneous-move game of emissions reduction and R\&D investments, we find that the equilibrium R\&D investment can be larger than the first best level in these examples.

Technological innovation is often induced by an international environmental agreement (IEA). In some cases, IEAs explicitly encourage the signatories to cooperate in R\&D. ${ }^{1}$ Several studies have examined how technology spillovers influence countries' cooperation in providing global public goods. ${ }^{2}$ Carraro and Siniscalco (1997) analyze the stability of IEAs assuming that the signatories conduct R\&D to develop a cleaner technology which is unavailable to non-signatories. Buchner et al. (2002) study the stability of climate change mitigation cooperation across countries when technology spillovers within cooperating countries are larger than spillovers from cooperating countries to non-cooperating countries. Barrett

\footnotetext{
${ }^{1}$ Examples include a six-country pact for developing technology to reduce greenhouse gas emissions. See "Vision Statement of Australia, China, India, Japan, the Republic of Korea, and the U.S. for a New Asia-Pacific Partnership on Clean Development and Climate," available at http://www.state.gov/g/oes/rls/fs/50335.htm.

${ }^{2}$ Heal (1993) and Barrett (2003) argue that abatement efforts and technology change in one country may reduce the marginal abatement costs in other countries and the first-best outcome may be supported once a sufficient number of countries adopt higher environmental standards.
} 
(2003) raises two questions about their approach (pp.309-310). First, it is often difficult to prevent technology diffusion once new technology is developed. Second, given that a cleaner technology is developed and signatories' environmental damage is increasing in nonsignatories' emissions, the signatories may have an incentive to allow the non-signatories to use the cleaner technology so that the global emissions decline. Barret (2003) also argues that no existing IEAs prevent the non-signatories from using new technology developed by the signatories. For example, the Montreal Protocol requires that parties cooperate in promoting R\&D for a technology that reduces controlled substances, where non-parties are allowed easy access to new technologies by the parties (Barret 2003, pp.309-10.) Indeed,there is a stronger argument against the idea that new technologies will not spill over: this is that the companies that develop them will want to sell them worldwide as part of a profit-maximization strategy. General Electric is aggressively promoting its carbon capture and storage technologies worldwide, though they were developed in the U.S.

To investigate countries' incentive for emission control and investments, we consider a simultaneous-move game where the countries choose investments and emissions simultaneously when both technology and pollution spill over across countries. We find the following (see Table 1).

1. If each country's marginal abatement cost is decreasing in R\&D investment, then the Nash equilibrium investments are lower and the equilibrium emissions are larger than the first-best levels. This result holds regardless of the degree of technology spillovers among countries. This is the "conventional wisdom" case.

2. If the marginal abatement costs are increasing in investment, then the equilibrium results in over-(under-)investment when the degree of spillovers is small (large) enough. In this case, emissions may be less than in the first best case. This case is contrary to conventional wisdom.

The first point is consistent with Golombek and Hoel (2004), who have the same finding under the assumptions listed above. The second point implies that whether the first claim holds depends on the relationship between R\&D and the marginal abatement costs. Section 2 discusses cases in which marginal abatement costs may increase under a new technology. 
Intuitively we can see why the movement of marginal abatement costs (MACs) is important. Suppose that technological development leads to an abatement technology with lower fixed and higher variable costs, and lower average costs - we will suggest below that this accurately describes one of the main technologies now being developed, that of carbon capture and storage. Then the lower fixed costs have an income effect which will typically lead to the choice of more abatement. However the higher MAC produces a substitution effect that acts in the opposite direction. In such a situation it is not clear whether the outcome will be more or less abatement. This is true for both the socially optimal allocation and the Nash equilibrium allocation, but it is stronger for the first best case and so tends to reduce abatement more, reduce emissions less, in this case. This opens up the possibility that Nash emissions may be less than the first best, as Nash abatement is reduced less. We show below that this can happen when spillovers are large: large spillovers tend of course to counteract the standard arguments about free riders and public goods. Large spillovers provide income effects to all countries, similarly to lower fixed costs. This explains why we find counterintuitive outcomes with small income effects.

[Table 1]

The next section discusses examples of technologies where the marginal abatement cost may decrease or increase as a result of technology innovation. Section 3 describes the assumption of our analysis, the result, and discussions regarding alternative assumptions. Section 4 concludes the paper with policy implications.

\section{Technology innovation and marginal abatement costs}

The relationship between marginal abatement costs and $R \& D$ is central to some of our results. We expect, of course, that abatement costs will fall as a result of successful R\&Dthat is in effect the definition of success in R\&D. Presumably we mean the total cost of attaining a given level of abatement falls, but this leaves open the impact of $R \& D$ on the fixed and variable costs of reducing emissions. In principle, successful R\&D can introduce a new technology whose cost structure is totally different from that of the current technology. The current technology may for example have high fixed and low variable costs, whereas the new one has low fixed costs and high variable costs. In this case the total and average costs 
would be lower but the marginal abatement cost might be higher with the new technology. These issues are discussed to some degree in Baker et al. (2006, 2008), who consider the effect of uncertainty about the costs of climate change on the optimal spending on R\&D: they find that the abatement cost curve can change in many different ways as a result of R\&D, depending on the parameters of the model. Bauman (2003) and Brechet and Jouvet (2006) also present theoretical models which demonstrate that the marginal abatement cost may be higher with new technology. The Economics of Climate Change (Stern Review, 2006) also notes that "step-change improvements in a technology might accelerate progress [of declining marginal costs], while constraints such as the availability of land or materials could result in increasing marginal costs" (Executive Summary, p.xx).

Researchers are currently investigating many different technologies for CO2 abatement. Integrated combined cycle coal gasification (ICCCG) with carbon capture and storage is one possibility: coal combustion with cryogenic oxygen and carbon capture and storage is another, and the use of renewable energy sources and nuclear power represent yet more alternatives. If we think of renewable energy and nuclear as the current abatement technologies, and ICCCG with C-capture and storage as a possible new technology, then the change in cost structures in going from the old to the new technologies is instructive. Renewable energy sources and nuclear have high fixed costs but almost no variable costs, so that the marginal cost of abatement along this route is close to zero even though the average is high. ICCCG with C-capture and storage, by contrast, would have high marginal costs: each ton of CO2 has to be captured (perhaps $\$ 5$ per ton) and then transported (perhaps $\$ 10$ per ton) and stored (perhaps $\$ 5$ per ton). We would not use this technology unless its average cost were less than renewables, but if we used it we would face a higher marginal cost. ${ }^{3}$

\section{A game with emissions and technology externality}

\subsection{Assumptions, the optimal outcome, and the symmetric Nash equilibrium}

Suppose $N$ countries choose R\&D investments and emissions for developing abatement technology. Let $\left(k_{i}, e_{i}\right) \geq 0$ be country $i$ 's investment and emissions choice. Country $i$ 's cost of

\footnotetext{
${ }^{3}$ We are grateful to Klaus Lackner for an instructive discussion of these issues.
} 
investing $k_{i}$ is given by $G\left(k_{i}\right) \geq 0$ where $G^{\prime}>0, G^{\prime \prime} \geq 0$. When the countries' investment profile is $k=\left(k_{1}, \ldots, k_{N}\right)$, country $i$ 's cost of reducing emissions from its status-quo level $\bar{e}>0$ to a level $e_{i} \geq 0$ is given by $C\left(e_{i}, z_{i}(k)\right) \geq 0$ where

$$
z_{i}(k)=k_{i}+\lambda \sum_{j \neq i} k_{j}
$$

The function $z_{i}$ represents the effective amount of abatement capital available to country $i$ given investment profile $k$. The exogenous parameter $\lambda \in[0,1]$ represents the extent of innovation spillovers across countries. There is no technology diffusion and R\&D is a private good if $\lambda=0$. With complete spillovers, $\lambda$ is equal to one. The abatement cost function $C$ is twice continuously differentiable and convex with $C_{e}<0, C_{z}<0, C_{e e}>0, C_{z z}>0$ for all $e<\bar{e}$. (Subscripts stand for partial derivatives.) We assume $C_{e z}$ is positive, zero, or negative. The marginal abatement cost $-C_{e}$ is decreasing in investment if $C_{e z}>0$. Given total emissions $E=\sum_{j} e_{j}$, country $i$ 's damage is $D(E) \geq 0$ where $D^{\prime}>0$ and $D^{\prime \prime}>0$.

We assume that the countries choose investment and emissions simultaneously. The main result of the paper will hold if the countries choose investment and emissions sequentially (i.e. they choose investment simultaneously first, and then emissions simultaneously).

The first-best investment emission and allocation $\left\{k_{i}^{*}, e_{i}^{*}\right\}$ minimizes the social cost of emissions $\sum_{i}\left[G\left(k_{i}\right)+C\left(e_{i}, z_{i}(k)\right)+D(E)\right]$. The first order condition for an interior solution is

$$
\begin{gathered}
G^{\prime}\left(k_{i}^{*}\right)+C_{z}\left(e_{i}^{*}, k_{i}^{*}+\lambda \sum_{j \neq i} k_{j}^{*}\right)+\sum_{j \neq i} \lambda C_{z}\left(e_{j}^{*}, k_{j}^{*}+\lambda \sum_{l \neq j} k_{l}^{*}\right)=0 \\
C_{e}\left(e_{i}^{*}, k_{i}^{*}+\sum_{j \neq i} k_{j}^{*}\right)+N D^{\prime}\left(\sum_{j} e_{j}^{*}\right)=0
\end{gathered}
$$

for $i=1, \ldots, N$. The symmetric solution where $\left(k_{i}^{*}, e_{i}^{*}\right)=\left(k_{j}^{*}, e_{j}^{*}\right) \equiv\left(k^{*}, e^{*}\right)$ for all $i, j \in I$ satisfies

$$
\begin{aligned}
G^{\prime}\left(k^{*}\right)+f(\lambda) C_{z}\left(e^{*}, f(\lambda) k^{*}\right) & =0 \\
C_{e}\left(e^{*}, f(\lambda) k^{*}\right)+N D^{\prime}\left(N e^{*}\right) & =0
\end{aligned}
$$

where $f(\lambda) \equiv 1+(N-1) \lambda$. Similarly, an interior Nash equilibrium $\left\{\widehat{k}_{i}, \widehat{e}_{i}\right\}$ satisfies

$$
G^{\prime}\left(\widehat{k}_{i}\right)+C_{z}\left(\widehat{e}_{i}, \widehat{k}_{i}+\lambda \sum_{j \neq i} \widehat{k}_{j}\right)=0, \quad C_{e}\left(\widehat{e}_{i}, \widehat{k}_{i}+\lambda \sum_{j \neq i} \widehat{k}_{j}\right)+D^{\prime}\left(\sum_{j} \widehat{e}_{j}\right)=0
$$

for all $i$. The symmetric Nash equilibrium $(\widehat{e}, \widehat{k})$ where $\left(\widehat{k}_{i}, \widehat{e}_{i}\right)=(\widehat{k}, \widehat{e})$ for all $i$ satisfies

$$
G^{\prime}(\widehat{k})+C_{z}(\widehat{e}, f(\lambda) \widehat{k})=0
$$




$$
C_{e}(\widehat{e}, f(\lambda) \widehat{k})+D^{\prime}(N \widehat{e})=0
$$

Under the assumptions on $C$ and $D$, we can solve conditions (2) and (4) for emissions as a function of investment in the first best allocation and in the Nash equilibrium. Call these functions $e^{f}$ and $e^{n}$. (Superscript $f$ stands for the first best and $n$ for Nash equilibrium. Note that $e^{f}\left(k^{*}\right)=e^{*}$ and $e^{n}(\widehat{k})=\widehat{e}$.) These functions satisfy the following property. (See the appendix for the proofs.)

Lemma $1 e^{n}(k)>e^{f}(k)$ for all $k>0$.

Lemma 2 If $C_{e z} \gtreqless 0$, then $\frac{d e^{f}}{d k} \lesseqgtr 0$ and $\frac{d e^{n}}{d k} \lesseqgtr 0$.

Lemma 3 The equilibrium investment by each country is decreasing in the degree of technology spillovers $\lambda$ (i.e. $\frac{\partial \widehat{k}}{\partial \lambda}<0$ ). The first-best investment by each country may be decreasing or increasing in technology spillovers. The equilibrium and the first best emissions are nonincreasing (nondecreasing) in $\lambda$ if $C_{e z}>(<) 0$.

Given the same investment level, the Nash equilibrium emission is larger than the first best level (Lemma 1). Both the equilibrium and the first best emissions are decreasing (increasing) in investment if the marginal abatement cost is decreasing (increasing) in investment (Lemma 2). See figure 3 for an example where the first-best investment may decrease when the degree of technology spillovers increases.

\subsection{Main results}

The following proposition is based on the three lemmas and compares the first best solution and the Nash equilibrium outcome of the game where countries choose investment and emissions simultaneously.

Proposition 1 Let $\left\{k^{*}, e^{*}\right\}$ be the first best investment and emission of each country and $\{\widehat{k}, \widehat{e}\}$ be the symmetric Nash equilibrium.

(i) If $C_{e z}>0$, then $\widehat{e}>e^{*}$ and $\widehat{k}<k^{*}$ for all $\lambda \in[0,1]$.

(ii) If $C_{e z}=0$ and $\lambda=0$, then $\widehat{e}>e^{*}$ and $\widehat{k}=k^{*}$. If $C_{e z}=0$ and $\lambda>0$, then $\widehat{e}>e^{*}$ and $\widehat{k}<k^{*}$. 
(iii) If $C_{e z}<0$ and $(N-1) \lambda<\frac{C_{z}\left(e^{n}(\widehat{k}), f(\lambda) \widehat{k}\right)}{C_{z}\left(e^{f}(\widehat{k}), f(\lambda) \widehat{k}\right)}-1$, then $\widehat{e}>e^{*}$ and $\widehat{k}>k^{*}$. If $C_{e z}<0$ and $(N-1) \lambda>\frac{C_{z}\left(e^{n}(\widehat{k}), f(\lambda) \widehat{k}\right)}{C_{z}\left(e^{f}(\widehat{k}), f(\lambda) \widehat{k}\right)}-1$, then $\widehat{k}<k^{*}$.

The equilibrium emission is larger than the first best level if the marginal abatement cost is nonincreasing in $\mathrm{R} \& \mathrm{D}$ or if the spillover effect is small. If the marginal abatement cost is decreasing in investment $\left(C_{e z}>0\right)$, then the equilibrium investment is smaller than the first best level regardless of the spillover effect $\lambda$. If $C_{e z}=0$, then the equilibrium investment is the same as the first best level under no spillover and under-investment occurs under spillovers. If the marginal abatement cost is increasing in investment $\left(C_{e z}<0\right)$, then over-investment occurs when spillovers and the number of countries are small while underinvestment occurs when spillovers or the number of countries are large. Larger marginal abatement costs imply larger ex-post optimal emissions and hence larger damages to each country. With small technology spillovers and the marginal abatement costs increasing in investments, each country's privately optimal investment exceeds the socially optimal investment.

Part (i) has been demonstrated in literature (e.g. Golombek and Hoel 2004) and perhaps not surprising. We explain part (iii) graphically by assuming $C_{e z}<0$. Figure 1 contrasts a representative country's optimal and equilibrium emission and investment choice. The figure also assumes $\lambda=0$, and hence the only source of externality is emissions. While the marginal abatement cost of each country equals the social (aggregate) marginal damages of all countries under the optimal outcome, the equilibrium emission equates the marginal abatement cost and the private marginal damages for each country (panel b). The assumption $C_{z e} \equiv C_{e z}<0$ implies that the marginal benefit of investment (i.e. the marginal reduction in abatement cost due to investment) is smaller under smaller emissions (see panel a), and hence the equilibrium investment exceeds the first best level. Figure 2 illustrates a case where the equilibrium emission is lower than the first best level. Given $\lambda>0$, technology spillover is an additional source of externality. The spillovers tend to lower the equilibrium investment relative to the first best level. With $\lambda$ sufficiently large, the equilibrium investment $\hat{k}$ exceeds the first best level $k^{*}$ and hence the marginal abatement cost curve given $\hat{k}$ lies to the left of the marginal abatement cost curve given $k^{*}$. Therefore, as in Figure 2, the equilibrium emission (given by the intersection of the marginal abatement cost given $\hat{k}$ and the private marginal damage) can fall below the first best emission (given by the intersection 
of the marginal abatement cost given $k^{*}$ and the social marginal damage) as in panel (b). ${ }^{4}$

[Figure 1]

[Figure 2]

\section{$3.3 \quad$ Example}

The following example illustrates the result of Proposition 1:

$$
G(k)=r k, \quad C(e, z)=f(z)+a(z)(\bar{e}-e)+\frac{b(z)}{2}(\bar{e}-e)^{2}, \quad D(E)=\frac{d}{2} E^{2},
$$

where the quantity $\bar{e}$ represents the emission level in the absence of abatement, and $\bar{e}-e$ the abatement level. The function $f$ represents the fixed cost of emission abatement. As explained in the previous section, $f$ may be decreasing or increasing in the effective capital $z$. We assume $f$ is strictly convex. At an emission level $e \in[0, \bar{e}]$, the marginal abatement cost is given by $a(z)+b(z)(\bar{e}-e)$ and its derivative with respect to investment is $a^{\prime}(z)+b^{\prime}(z)(\bar{e}-e)$. For simplicity, assume

$$
f(z)=f_{0}+f_{1} z+\frac{f_{2}}{2} z^{2}, \quad a(z)=a z, \quad b(z) \equiv b,
$$

for all $z \geq 0$ where $f_{2}$ and $b$ are positive while $f_{1}$ and $a$ may be positive or negative. New technology results in either lower marginal abatement cost, lower fixed cost of abatement, or both. If $f_{1}>0$ and $a>0$, then investment results in technologies with lower fixed costs and larger marginal abatement cost. If $a<0$, then investment results in smaller marginal abatement cost. Convexity of $C$ requires $b f_{2}-a^{2} \geq 0$.

[Figure 3]

Figure 3 illustrates the result of Proposition 1 using the above example with $a=1, b=$ $1, d=.75, N=2, r=1.5, f_{1}=2, f_{2}=1, \bar{e}=.5$. (Note that $a>0$ implies $C_{e z}<0$, i.e. the marginal abatement cost is increasing in investment.) This example illustrates part (iii) of Proposition 1:

- With small technology spillovers, the equilibrium emissions are larger than the optimal level. The equilibrium investment level is larger than the optimal level.

\footnotetext{
${ }^{4}$ Though the figure assumes that $G^{\prime \prime}=0$, the argument is also valid when $G^{\prime \prime}>0$.
} 
- With large technology spillovers, the equilibrium emissions are smaller than the optimal level. The equilibrium investment level is smaller than the optimal level.

As discussed in section 1, this example corresponds to the case where the current technology is renewable energy and the new technology is ICCCG with carbon capture. When the spillover effect is small, the equilibrium may result in over-investment. When the spillover effect is large, the equilibrium may result in under-emissions.

Proposition 1 states that the equilibrium emission exceeds the optimal level whenever the equilibrium investment is larger than the optimal level. Figure 3 demonstrates that the equilibrium emissions can exceed the first best level when the equilibrium investment is smaller than the optimal level. As in Lemma 2, both the equilibrium and optimal emissions are increasing in investment when the marginal abatement cost is increasing in investment. Hence, when under-investment occurs at the equilibrium, the equilibrium emissions may fall below the optimal level. However, as Figure 4 illustrates, the equilibrium emissions are not necessarily smaller than the optimal level when $\lambda$ is large.

[Figure 4]

\subsection{Investment and emissions under alternative assumptions}

We discuss the results under alternative assumptions.

We assumed that the countries choose investment and emissions simultaneously. It might be more natural to assume that the countries choose investment first and then emissions. The result about over-investment under increasing marginal abatement cost holds under the alternative assumption of sequential move.

Though we present our result in the context of transboundary pollution with countries as players, our analysis has an implication to domestic environmental regulation with a regulator and regulated firms as players. A large number of studies have compared regulated firms' incentive for technology innovation and adoption under alternative emission regulation (such as emissions quantity standards, emissions taxes, and emissions trading, see Milliman and Prince 1989, Requate et al. 2003, Newell and Jaffe et al. 2003). A number of studies have found that, when the regulator sets emissions standards or emissions taxes after the firms conduct investment, the regulated firms have an incentive to over-invest (relative to 
the optimal level) under taxes and under-invest under standards (Malik 1991, Kennedy and Laplante 1999, Karp and Zhang 2002, Moledina et al. 2003, Tarui and Polasky 2006). They assume that the marginal abatement costs are decreasing in investment. If the marginal abatement costs are increasing investment, then the opposite incentive will work under taxes and standards. Baker et al. (2008) present a thorough summary of the implications of the increasing marginal abatement costs and provide a raking of alternative emission policy instruments under the assumption.

The analysis in this section assumed that the countries are identical. A more realistic model would assume that countries differ in abatement costs and pollution damage functions. With heterogeneity, the equilibrium investment (emission) of some countries may be larger (lower) than the first best level even if the marginal abatement cost is decreasing in investment. This possibility is analogous to the free-rider problem associated with the private provision of public goods: with heterogenous players, those who would benefit most (less) from public goods may contribute more (less) to the supply of public goods.

\section{Discussion}

This paper studied countries' incentives to reduce emissions of pollutants and develop a new emission abatement technology when technology diffusion across countries may occur and emission reduction is a global public good. If the marginal abatement cost of each country is decreasing in investment, then the Nash equilibrium results in excessive emissions and under-investment in innovation relative to the first-best under any degree of technology spillovers. The equilibrium results in over-investment when spillovers are small enough and if the marginal abatement cost is increasing in investment.

Our study is motivated in part by the problem of global climate change: it is clear that a comprehensive solution needs new technologies, that solving the problem is providing a global public good, and that the trade-offs we model here are central to policy choices about funding $\mathrm{R} \& \mathrm{D}$ and about treaty formats. Our finding implies that the direction to which the incentives for investments and emission reduction are biased depends on the types of technologies involved and the degree of technology spillovers. In particular, the transitions from one pollution abatement technology to another do not necessarily justify subsidizing 
it even if the emission causes a negative externality. Though the model applies to transboundary pollution and technology spillovers across countries, the implication extends to environmental regulation on industries in a domestic context as well (see section 3.4).

We did not consider several important aspects of investments and emission reduction in international and national contexts such as government-industry interactions (firms' incentive to innovate given costly R\&D and/or patenting or licensing opportunities given imperfect appropriability of innovation), heterogeneity among countries, and dynamics (changes in technology, atmospheric $\mathrm{CO}_{2}$ concentration, and treaty participation over time). We assumed deterministic innovation. ${ }^{5}$ Though some of these issues are discussed in the previous section, further analysis is left for future research.

\section{Appendix}

\section{Proof of Lemma 1}

We have

$C_{e}\left(e^{n}(k), f(\lambda) k\right)+N D^{\prime}\left(N e^{n}(k)\right)=C_{e}\left(e^{n}(k), f(\lambda) k\right)+D^{\prime}\left(N e^{n}(k)\right)+(N-1) D^{\prime}\left(N e^{n}(k)\right)>0$

for all $k>0$ by condition (4). Because $C_{e}+N D^{\prime}$ is increasing in emissions, it follows that $e^{n}(k)>e^{f}(k)$ for all $k>0$.

\section{Proof of Lemma 2}

Totally differentiate condition $(2)$ with respect to $e^{*}$ and $k^{*}$ to obtain

$$
C_{e e} d e^{*}+f(\lambda) C_{e z} d k^{*}+N^{2} D^{\prime \prime} d e^{*}=0, \quad \text { i.e. } \quad \frac{d e^{f}}{d k}=\frac{-f(\lambda) C_{e z}}{C_{e e}+N^{2} D^{\prime \prime}}
$$

which is positive if $C_{e z}<0$ and negative if $C_{e z}>0$. Similarly, total differentiation of condition (4) yields

$$
C_{e e} d \widehat{e}+f(\lambda) C_{e z} d k+N D^{\prime \prime} d \widehat{e}=0, \quad \text { i.e. } \quad \frac{d e^{n}}{d k}=\frac{-f(\lambda) C_{e z}}{C_{e e}+N D^{\prime \prime}}
$$

which is positive if $C_{e z}<0$ and negative if $C_{e z}>0$.

\footnotetext{
${ }^{5}$ For the analysis of IEAs with stochastic technological change, see Kolstad (2007).
} 


\section{Proof of Lemma 3}

Differentiate the equations (3) and (4) with respect to $\lambda$ and obtain

$$
\left(\begin{array}{cc}
G^{\prime \prime}+f(\lambda) C_{z z} & C_{z e} \\
f(\lambda) C_{e z} & C_{e e}+N D^{\prime \prime}
\end{array}\right)\left(\begin{array}{c}
\frac{\partial \widehat{k}}{\partial \lambda} \\
\frac{\partial \hat{e}}{\partial \lambda}
\end{array}\right)=\left(\begin{array}{c}
-f^{\prime}(\lambda) \widehat{k} C_{z z} \\
-f^{\prime}(\lambda) \widehat{k} C_{e z}
\end{array}\right) .
$$

Applying Cramer's Rule, we have

$$
\frac{\partial \widehat{e}}{\partial \lambda}=\frac{-f^{\prime}(\lambda) \widehat{k} G^{\prime \prime} C_{e z}}{A}, \quad \frac{\partial \widehat{k}}{\partial \lambda}=\frac{-f^{\prime}(\lambda) \widehat{k}\left[\left\{C_{e e} C_{z z}-C_{e z}^{2}\right\}+N C_{z z} D^{\prime \prime}\right]}{A}
$$

where

$$
A \equiv G^{\prime \prime}\left(C_{e e}+N D^{\prime \prime}\right)+f(\lambda)\left\{C_{e e} C_{z z}-C_{e z}^{2}\right\}+N f(\lambda) C_{z z} D^{\prime \prime}>0 .
$$

Therefore, $\frac{\partial \widehat{e}}{\partial \lambda} \leq(\geq) 0$ if $C_{e z} \geq(\leq) 0$. The equilibrium investment is decreasing in $\lambda\left(\frac{\partial \widehat{k}}{\partial \lambda}<0\right)$ regardless of the sign of $C_{e z}$.

Similarly, differentiate the equations (1) and (2) with respect to $\lambda$ and obtain

$$
\left(\begin{array}{cc}
G^{\prime \prime}+f^{2} C_{z z} & f C_{z e} \\
f C_{e z} & C_{e e}+N^{2} D^{\prime \prime}
\end{array}\right)\left(\begin{array}{c}
\frac{\partial k^{*}}{\partial \lambda} \\
\frac{\partial e^{*}}{\partial \lambda}
\end{array}\right)=\left(\begin{array}{c}
-f^{\prime} C_{z}-f f^{\prime} k^{*} C_{z z} \\
-f^{\prime} k^{*} C_{e z}
\end{array}\right) .
$$

Solving for $\frac{\partial k^{*}}{\partial \lambda}$ and $\frac{\partial e^{*}}{\partial \lambda}$, we have

$\frac{\partial e^{*}}{\partial \lambda}=\frac{-f^{\prime} C_{e z}\left[G^{\prime \prime} k^{*}-f C_{z}\right]}{B}, \quad \frac{\partial k^{*}}{\partial \lambda}=\frac{-f^{\prime} C_{z}\left(C_{e e}+N^{2} D^{\prime \prime}\right)-f f^{\prime} k^{*}\left[\left\{C_{e e} C_{z z}-C_{e z}^{2}\right\}+N^{2} C_{z z} D^{\prime \prime}\right]}{B}$

where

$$
B \equiv G^{\prime \prime}\left(C_{e e}+N^{2} D^{\prime \prime}\right)+f^{2}\left\{C_{e e} C_{z z}-C_{e z}^{2}\right\}+f^{2} N^{2} C_{z z} D^{\prime \prime}>0 .
$$

Therefore, $\frac{\partial e^{*}}{\partial \lambda}<(>) 0$ if $C_{e z}>(<) 0$. The sign of $\frac{\partial k^{*}}{\partial \lambda}$ is indeterminate.

\section{Proof of Proposition 1}

To show (i), suppose $C_{e z}>0$. As in the proof of lemma 3 , the first best investment $k^{*}$ satisfies

$$
F^{*}\left(k^{*}\right) \equiv G^{\prime}\left(k^{*}\right)+f(\lambda) C_{z}\left(e^{f}\left(k^{*}\right), f(\lambda) k^{*}\right)=0 .
$$

Similarly, the equilibrium investment $\widehat{k}$ satisfies

$$
F(\widehat{k}) \equiv G^{\prime}(\widehat{k})+C_{z}\left(e^{n}(\widehat{k}), f(\lambda) \widehat{k}\right)=0
$$


Note that $\frac{d e^{f}}{d k}<0$ and $\frac{d e^{n}}{d k}<0$ by lemma 2 and $C_{e z}>0$. For any $k \geq 0$ we have

$$
\begin{gathered}
F^{*}(k)-F(k)=f(\lambda) C_{z}\left(e^{f}(k), f(\lambda) k\right)-C_{z}\left(e^{n}(k), f(\lambda) k\right) \\
\leq C_{z}\left(e^{f}(k), f(\lambda) k\right)-C_{z}\left(e^{n}(k), f(\lambda) k\right)
\end{gathered}
$$

where the last inequality follows from $C_{z}<0$ and $f(\lambda) \geq 1$ for all $\lambda \in[0,1]$. Because $C_{z e}>0$ by assumption and $e^{f}(k)<e^{n}(k)$ by lemma 1 , we have $C_{z}\left(e^{f}(k), f(\lambda) k\right)-C_{z}\left(e^{n}(k), f(\lambda) k\right)<$ 0 . Hence, $\widehat{k}$ (that satisfies $F(\widehat{k})=0$ ) must be smaller than $k^{*}$ (that satisfies $F^{*}\left(k^{*}\right)=0$ ) regardless of the value of $\lambda$. Finally, $\widehat{k}<k^{*}$ implies $\widehat{e}=e^{n}(\widehat{k})>e^{n}\left(k^{*}\right)>e^{f}\left(k^{*}\right)=e^{*}$.

To show (ii), suppose $C_{e z}=0$. Then conditions (1) and (2) are equivalent to

$$
\begin{gathered}
G^{\prime}\left(k^{*}\right)+f(\lambda) \phi_{k}\left(f(\lambda) k^{*}\right)=0, \\
\phi_{e}\left(e^{*}\right)+N D^{\prime}\left(N e^{*}\right)=0
\end{gathered}
$$

where $\phi_{k}(z) \equiv C_{z}(e, z)$ for all $e, z$ and $\phi_{e}(e) \equiv C_{e}(e, z)$ for all $e, z$. These two conditions determine the first best invest and emission independently. Similarly, conditions (3) and (4) for the Nash equilibrium are equivalent to

$$
\begin{gathered}
G^{\prime}(\widehat{k})+\phi_{k}(f(\lambda) \widehat{k})=0 \\
\phi_{e}(\widehat{e})+D^{\prime}(N \widehat{e})=0
\end{gathered}
$$

Lemma 1 implies $\widehat{e}>e^{*}$ for any $\lambda$. If $\lambda=0$, then conditions (7) and (8) are identical and hence $\widehat{k}=k^{*}$. If $\lambda>0$, then

$G^{\prime}(k)+\phi_{k}(f(\lambda) k)=G^{\prime}(k)+f(\lambda) \phi_{k}(f(\lambda) k)-(f(\lambda)-1) \phi_{k}(f(\lambda) k)>G^{\prime}(k)+f(\lambda) \phi_{k}(f(\lambda) k)$

for all $k$ because $\phi_{k}<0$. If follows from $G^{\prime \prime}+\phi_{k}^{\prime}>0$ that $\widehat{k}<k^{*}$.

To show (iii), suppose $C_{e z}<0$. If $\lambda=0$, then

$$
F^{*}(k)-F(k)=C_{z}\left(e^{f}(k), k\right)-C_{z}\left(e^{n}(k), k\right)
$$

where $e^{f}(k)<e^{n}(k)$ for all $k$ by lemma 1 . Because $C_{z e}<0$, we have

$$
C_{z}\left(e^{f}(k), k\right)>C_{z}\left(e^{n}(k), k\right)
$$


for all $k$. Hence, $F^{*}(k)-F(k)>0$ for all $k$. This implies that $\widehat{k}>k^{*}$. Emissions satisfy $\widehat{e}=e^{n}(\widehat{k})>e^{f}(\widehat{k})>e^{f}\left(k^{*}\right)=e^{*}$ where the last inequality follows from lemma 2 and the assumption $C_{e z}<0$.

For $\lambda>0$, suppose $F^{*}(\widehat{k})>0$. Then we have $\widehat{k}>k^{*}$ because

$$
F^{* \prime}=G^{\prime \prime}+f(\lambda) C_{z e} \frac{d e^{f}}{d k}+(f(\lambda))^{2} C_{z z}=G^{\prime \prime}+\frac{(f(\lambda))^{2}\left[C_{e e} C_{z z}-C_{z e}^{2}+N^{2} C_{z z} D^{\prime \prime}\right]}{C_{e e}+N^{2} D^{\prime \prime}}>0 .
$$

Inequality $\widehat{k}>k^{*}$ also implies $\widehat{e}=e^{n}(\widehat{k})>e^{f}(\widehat{k})>e^{f}\left(k^{*}\right)=e^{*}$. It follows from $F(\widehat{k})=0$ that $F^{*}(\widehat{k})-F(\widehat{k})>0$, i.e.

$$
f(\lambda) C_{z}\left(e^{f}(\widehat{k}), f(\lambda) \widehat{k}\right)-C_{z}\left(e^{n}(\widehat{k}), f(\lambda) \widehat{k}\right)>0
$$

Because $C_{z}<0$ and $f(\lambda)=1+(N-1) \lambda$, this inequality is equivalent to

$$
(N-1) \lambda<\frac{C_{z}\left(e^{n}(\widehat{k}), f(\lambda) \widehat{k}\right)}{C_{z}\left(e^{f(\widehat{k}), f(\lambda) \widehat{k})}\right.}-1 .
$$

Because $C_{z}<0, C_{z e}<0$ and $e^{n}>e^{k}$, the right hand side is positive. The inequality (9) implies $\widehat{k}>k^{*}$ and $\widehat{e}>e^{*}$. We have $\widehat{k} \leq k^{*}$ if (9) does not hold.

\section{References}

[1] Baker, E., Clarke, L., Weyant, J., 2006. Optimal Technology R\&D in the Face of Climate Uncertainty. Climatic Change 75, 157-180.

[2] Baker, E., Clarke, L., Shittu, E., 2008. Technical Change and the Marginal Cost of Abatement. Energy Economics, forthcoming.

[3] Barrett, S., 2003. Environment and Statecraft. Oxford University Press, Oxford, UK.

[4] Bauman, Y. K. 2003. The Effects of Environmental Policy on Technological Change in Pollution Control. PhD Dissertation, University of Washington.

[5] Brechet, T., Jouvet, P.-A. 2006. Environmental Innovation and the Cost of Pollution Abatement. Presented at the Third World Congress of Environmental and Resource Economists, July 2006. 
[6] Buchner, B., Carraro, C. Cersosimo, I., Marchiori, C. 2002. Back to Kyoto? US Participation and the Linkage between R\&D and Climate Cooperation. FEEM Working Paper 22.2002, Fondazione Eni Enrico Mattei.

[7] Carraro, C., Siniscalco, D. 1997. R\&D Cooperation and the Stability of International Environmental Agreements. In C. Carraro ed. International Environmental Negotiations, Edward Elgar Publishing, Cheltenham.

[8] Golombek, R., Hoel, M. 2004. The Kyoto Agreement and Technology Spillovers. University of Oslo, Working paper.

[9] Heal, G. 1993. Formation of International Environmental Agreements, in C. Carraro ed. Trade, Innovation, Environment, Kluwer, Dordrecht.

[10] Jaffe, A.B., Newell, R. G., Stavins, R. N., 2003. Technology change and the environment, in K.G. Mäler, J. Vincent (Eds.), Handbook of Environmental Economics, North Holland/Elsevier Science, Amsterdam.

[11] Karp,L., Zhang, J., 2002. Controlling a stock pollutant with endogenous investment and asymmetric information, Working Paper, Department of Agricultural and Resource Economics, University of California, Berkeley, CA

[12] Kennedy, P. W., Laplante, B., 1999. Environmental policy and time consistency: emission taxes and emissions trading, in Petrakis, E., Sartzetakis, E. S., Xepapadeas, A. (Eds.), Environmental Regulation and Market Power, Edward Elgar, Cheltenham, pp.116-144.

[13] Kolstad, C., 2007. Systematic uncertainty in self-enforcing international environmental agreements. Journal of Environmental Economics and Management, 53, 1, 68-79.

[14] Malik, A.S., 1991. Permanent versus interim regulations: A game-theoretic analysis. Journal of Environmental Economics and Management, 21, 2, 127-139.

[15] Milliman,S.R., Prince, R., 1989. Firm incentives to promote technological change in pollution, Journal of Environmental Economics and Management, 17, 292-296. 
[16] Moledina, A. A., Coggins, J. S., Polasky, S., Costello, C., 2003. Dynamic environmental policy with strategic firms: prices versus quantities, Journal of Environmental Economics and Management, 45, 356-376.

[17] Requate, T., Unold, W., 2003. Environmental policy incentives to adopt advanced abatement technology: Will the true ranking please stand up? European Economic Review, 47, 125-146.

[18] Stern, N., 2006. The Economics of Climate Change: The Stern Review. H.M. Treasury, U.K. 
Table 1: Equilibrium outcome of simultaneous-move games

\begin{tabular}{ccccc}
\multirow{2}{*}{$\begin{array}{c}\text { Technology } \\
\text { spillovers }\end{array}$} & \multicolumn{3}{c}{ Marginal abatement costs } \\
\cline { 3 - 5 } & Decreasing in R\&D & \multicolumn{2}{c}{ Increasing in R\&D } \\
\cline { 2 - 5 } & Emissions & Investment & Emissions & Investment \\
\hline Small & Too large & Too small & Too large & Too large \\
Large & Too large & Too small & $?$ & Too small
\end{tabular}



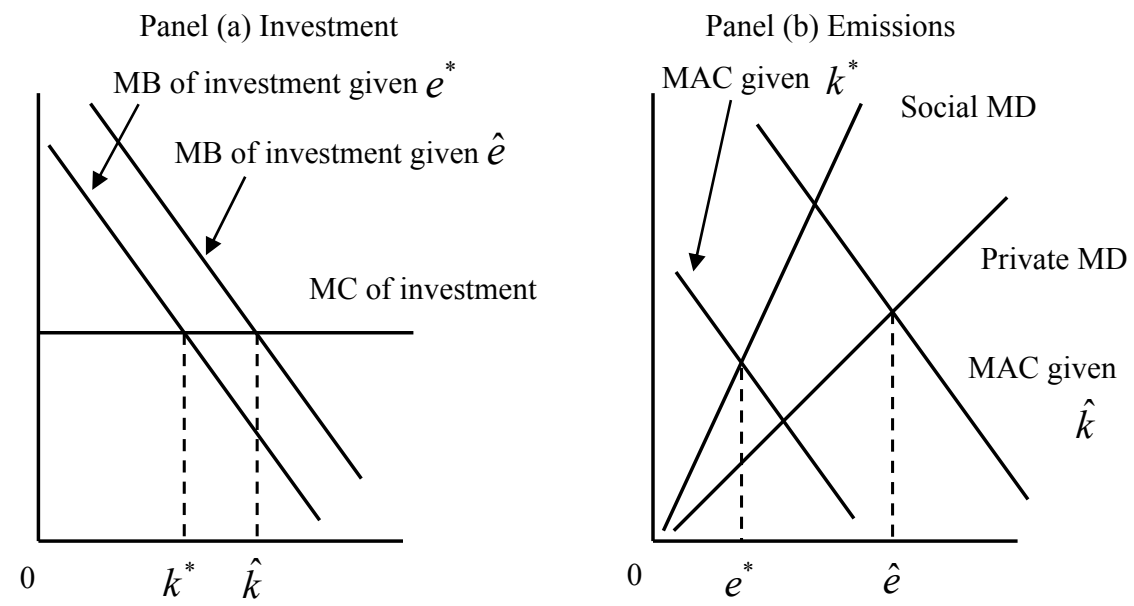

$\mathrm{MB}$ of investment is the negative of the partial derivative of abatement cost with respect to investment. MC of investment is the derivative of investment cost. MAC is the negative of the partial derivative of abatement codst with respect to emissions. Private and social MD refer to the marginal damage at a country level and at the aggregate, global level.

Figure 1: The equilibrium and the first best when $C_{e z}<0$ and $\lambda=0$.
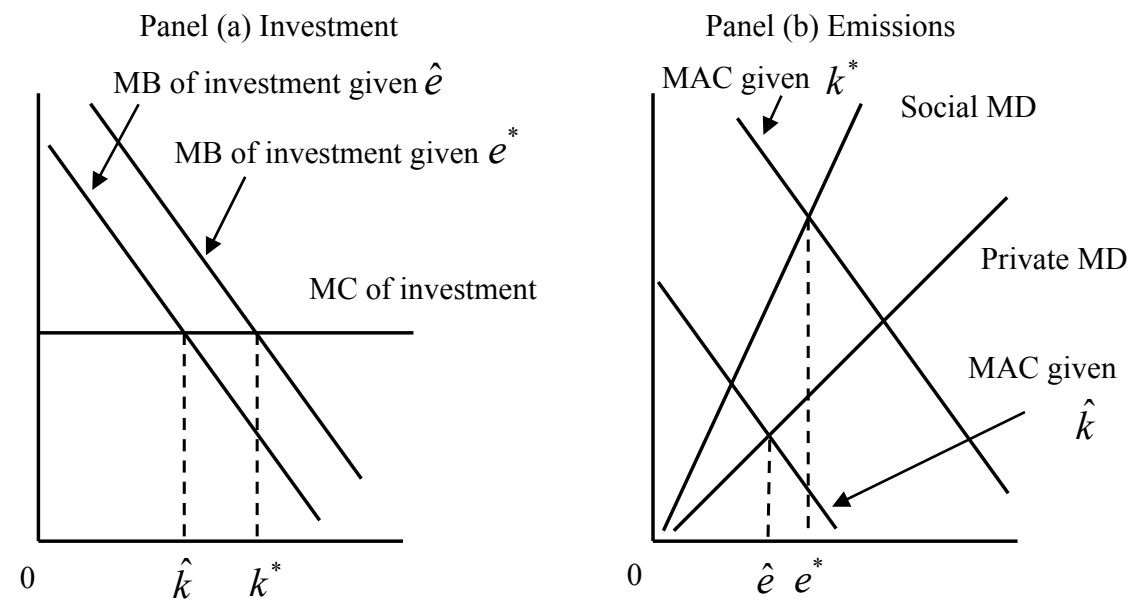

$\mathrm{MB}$ of investment is the negative of the partial derivative of abatement cost with respect to investment. MC of investment is the derivative of investment cost. MAC is the negative of the partial derivative of abatement codst with respect to emissions. Private and social MD refer to the marginal damage at a country level and at the aggregate, global level.

Figure 2: The equilibrium and the first best when $C_{e z}<0$ and a large $\lambda$. 

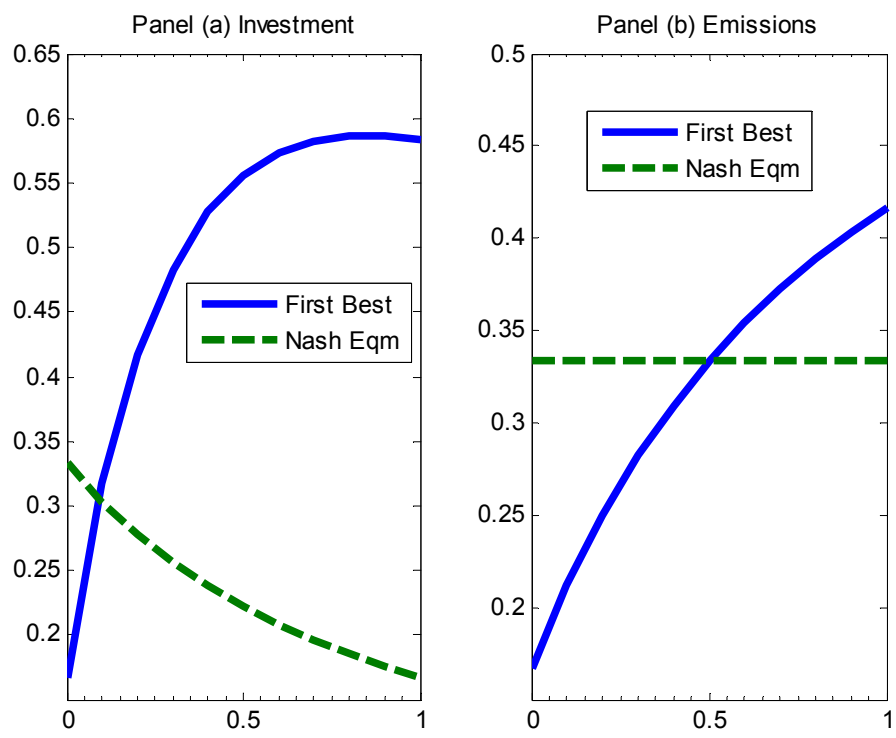

The figure is based on a linear quadratic example (equations 5,6 ) with $\mathrm{a}=1$, $\mathrm{b}=1, \mathrm{~d}=.75, \mathrm{~N}=2, \mathrm{r}=1.5, \mathrm{f}_{1}=2, \mathrm{f}_{2}=1, \bar{e}=.5$. In the two panels, the horizontal axes measure the degree of spillovers ( 0 : no spillovers, 1 : highest degree of spillovers).

Figure 3: The equilibrium and the first best when $C_{e z}<0$.
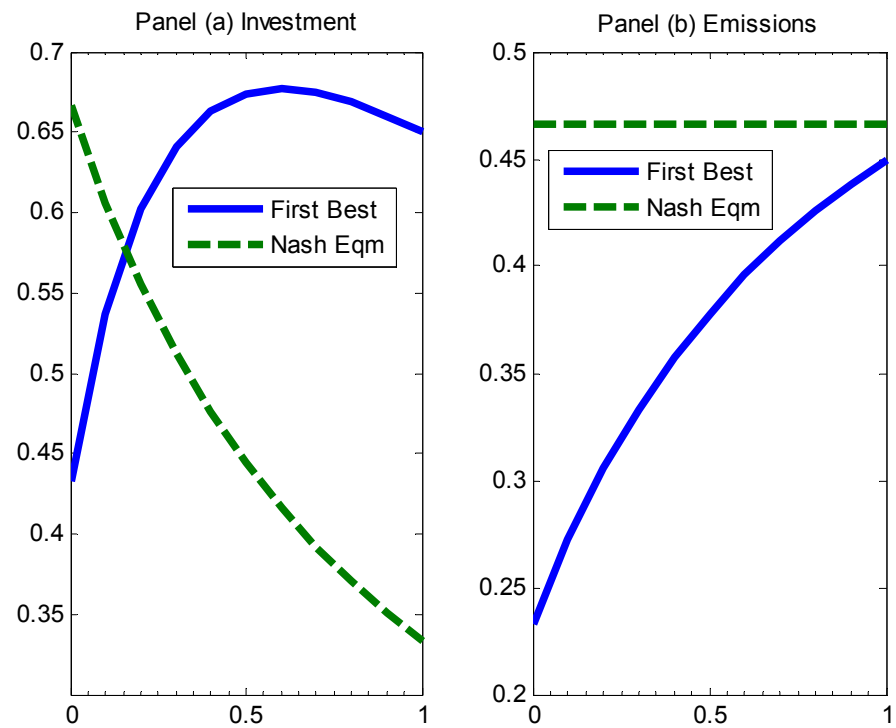

The figure is based on a linear quadratic example (equations 5,6) with $\mathrm{a}=1$, $\mathrm{b}=1, \mathrm{~d}=.75, \mathrm{~N}=2, \mathrm{r}=1.3, \mathrm{f}_{1}=2, \mathrm{f}_{2}=1, \bar{e}=.5$. In the two panels, the horizontal axes measure the degree of spillovers ( 0 : no spillovers, 1: highest degree of spillovers).

Figure 4: The equilibrium and the first best when $C_{e z}<0(2)$. 